is a 12 roomed house within the DGH site which could be used as a base.

The 'Grimmsville University Trust Hospital' in a neighbouring Health District offers a regional child and adolescent psychiatric service which also caters for children with mental handicap. The 'Grimmsville Trust' is in serious financial difficulty and Professors Freakout (Mental Handicap), Dubious (Child and Adolescent Psychiatry) and Boring (Psychology) have put together a very attractive bid for the above funding. Additionally, there are a number of charitable organisations which have been lobbying the DHA, and a number of interested private-forprofit competitors.

\section{Small group workshop I}

'Providers' divide into subgroups to assemble a bid, helped by facilitators. Each 'provider' subgroup elects a spokesperson (their 'clinical director') who will later present that bid to the 'purchaser' members of the respective group. All the 'purchasers', meanwhile, meet together with a facilitator (ideally a real life NHS purchaser manager) to determine the priority issues which they would want the 'providers' bid to address.

\section{Small group workshop II}

The combined 'purchaser' group now splits up, and the 'purchaser' and 'provider' members of the small groups meet. 'Provider' spokespersons present the bid to the three or four 'purchasers' across a 'boardroom table' observed by the other group members, who report on their observations in the concluding feedback-discussion session.

\section{Comment}

The workshop was attended by an equal ratio of senior and junior trainees who reported that the proceedings were enjoyable and highly educational.
Many had not previously contemplated the complexities of service delivery, and the wider aspects of the health needs of communities. The subspecialty of mental handicap was chosen for the exercise because few people knew anything about it, which facilitated the adherence to principle rather than detail. Even so, because of time constraints, group facilitators needed to be quite directive to prevent the groups from getting bogged down in minor detail. Most trainees reported that they had felt pressured, but produced some quite comprehensive bids nevertheless.

The workshop could possibly be improved by extending the time allocated to the small group workshops and by allowing more time for discussion; furthermore, by enabling each trainee to participate in, alternately, a 'purchaser' and a 'provider' group.

\section{Acknowledgement}

Sincere thanks to Mr Rob Wall, Chief Executive of the Mersey Purchasing Consortium, for joining in the game.

\section{References}

CTC Working Party Report on Management Training (1990) Psychiatric Bulletin, 14, 373-376.

Higgins, J. (1989) Management training in psychiatric practice: Proceedings of the 1989 Open Forum of the Education Committee of the Royal College of Psychiatrists. Psychiatric Bulletin, 13, 456-459.

LoCK, T. (1991) The response of psychiatric trainees to the implications of changes in postgraduate medical education: proceedings of the 1991 Open Forum of the Education Committee of the Royal College of Psychiatrists. Psychiatric Bulletin, 16, 556-557.

Ross, P. (1991) Doctors should become managers. BMA News Review, April 1991, 17.

\title{
Winston Churchill Travelling Fellowship
}

Workers in various fields including 'The Use and Abuse of Antibiotics and Tranquillisers' and 'Psychiatric Care' will be considered for a Winston Churchill Travelling Fellowship. Applications will be considered from 1 September and the closing date for receipt of completed application forms is 30 October 1992. Application forms are available from The Winston Churchill Memorial Trust, 15 Queen's Gate Terrace, London SW7 5PR. Please send a selfaddressed stamped envelope $(22 \mathrm{~cm} \times 11 \mathrm{~cm})$. 